\title{
cross Canada, healthcare systems are grappling with issues related to over-crowded and backed up emergency departments.
}

This issue of Healthcare Quarterly features a piece by Robert McKim and colleagues from the Capital Health Region in Edmonton where an Emergency Department Patient Feedback Survey was conducted in 2005 to obtain information on patient perceptions of satisfaction with services received. Perhaps not surprisingly, the survey results showed significant demographic and acuity differences in perceptions of care and suggested the need to consider patient mix in future satisfaction surveys. The authors also concluded that improvement strategies should be targeted at specific patient groups.

Another serious issue facing healthcare organizations is infection control. A second feature in this issue from Yassi et al., describes a British Columbian study in which workers in 16 healthcare facilities were surveyed about their compliance with infection control procedures. Perhaps not surprisingly, the results indicated that compliance is tied to the culture of the organization, suggesting that it is important to promote and maintain a 'safety culture' throughout an organization.

A recent survey of Healthcare Quarterly readers rated 'leadership' as a topic of high interest. In the Perspective section, we are pleased to initiate a series on key leadership behaviours and strategies that lead to best results. The series is based on a study by Starfield Consulting in which in-depth interviews were conducted with 40 senior leaders in the healthcare and public sectors. Those invited to participate had successfully led initiatives involving multiple organizations and were acknowledged as successful within the community. Part one looks at how leaders achieve success in change initiatives.

The Ideas at Work section presents two excellent examples of best practices worth sharing. The first piece from Credit Valley Hospital in Mississauga Ontario, describes lessons learned from a major construction project that was not only completed on time and \$10-million under budget but also provided end users with a facility that far exceeded expectations. The second piece from the University Health Network in Toronto describes a job rotation initiative that is earning high marks with employees.

The case study in this issue describes a process devised at a long-term care facility in British Columbia in which major renovations of dementia care units were carried out while the residents remained in the units. The authors describe the process as challenging but successful because of careful planning and phasing, the hiring of a contractor and workers who were sensitive to the needs of the residents and, of course, constant communication between stakeholders.
In our Futurethink section we have reprinted a column from Prof. Robert Evans at the University of British Columbia, which originally appeared in Health Policy (Vol. 2, No. 2). The piece, "Fat Zombies, Pleistocene Tastes, Autophilia and the 'Obesity Epidemic," suggests that "Canadians are fat and getting fatter ...By actual measurement, nearly a quarter of us (adults) are obese. So what?" Evans challenges us to think about obesity not as a healthcare crisis in-waiting but rather as a challenge that can be rectified with more thought to life-styles, urban planning and other determinants of health. A brilliant piece and well-worth several reads!

We are also delighted to publish an interview with Sister Elizabeth Davis who will be well-known to many of our readers. I met Sister Elizabeth many years ago when she was a graduate student in the Master's program at the University of Toronto. I say a graduate student - when it fact she was much wiser and had more to offer her classmates than the majority of the Faculty! We have kept in contact intermittently and I am in constant admiration of her achievements as a healthcare leader and role model for future leaders.

The regular columns in this issue deal with a range of pertinent topics - how the healthcare system treats obese patients; the impact of asthma on our system and what we can learn from repeat admissions to hospital. We are also pleased to present highlights and data from CIHI's new report on healthcare spending in the Quarterly Index section on page 152. In this edition of Longwoods Review, a paper by Pink et al., Selection of Key Financial Indicators: A Literature, Panel and Survey Approach, describes the methodology used to select the key financial indicators that are used in Ontario's Hospital Report surveys - one of the largest publicly-available, performance reporting initiatives in the world. More than 20 reports have been produced to date, including acute care, emergency department care, complex continuing care, rehabilitation, mental health, nursing and women's health.

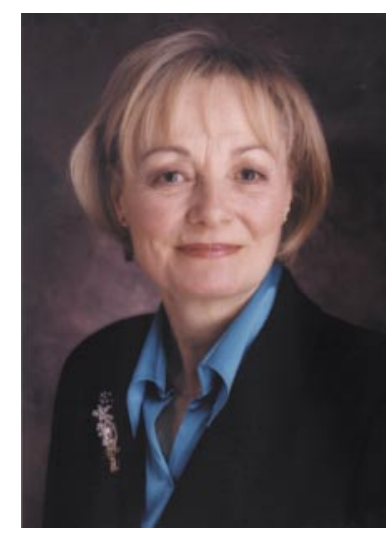

Commentaries are provided by Bruce Boissonnault, President and CEO, Niagara Health Quality Coalition and Ida Goodreau, President and CEO, Vancouver Coastal Health.

I would also like to mention that with this issue, Healthcare Quarterly enters its 10th year of publication. Regular readers will notice a refreshed design aimed at making the journal easier to read and more inviting. As always we welcome your letters and comments. HO

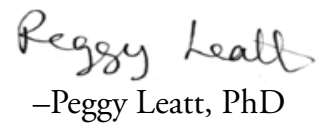

